\title{
Calcium dobesilate for diabetic retinopathy: a systematic review and meta-analysis
}

\author{
ZHANG XinYuan ${ }^{1 *}$, LIU Wei ${ }^{1,2}$, WU ShanShan ${ }^{3}$, JIN JingLong $^{4}$, LI WeiHong $^{4} \&$ \\ Wang NingLi ${ }^{1}$ \\ ${ }^{1}$ Beijing Institute of Ophthalmology, Tongren Eye Centre, Tongren Hospital, Capital Medical University, Beijing 100730, China; \\ ${ }^{2}$ University of Science and Technology Beijing, 30 Xueyuan Road, Haidian District, Beijing 100083, China; \\ 3Department of medical resources, Beijing Tongren Hospital, Capital Medical University, Beijing 100730, China; \\ ${ }^{4}$ Department of Epidemiology and Bio-statistics, Peking University Health Science Center, Beijing100191, China
}

Received October 12, 2014; accepted December 3, 2014; published online December 18, 2014

\begin{abstract}
Many randomized clinical controlled trials have confirmed the efficacy and safety of calcium dobesilate in treating diabetic retinopathy (DR). This systematic review critically evaluated the evidence that links calcium dobesilate to DR.In this fixed-effects meta-analysis, a total of 221 pertinent English-language articles published between January 1975 and October 2013 were identified. Systematic searches of PUBMED, Springer Link and the Cochrane Clinical Trials Database were conducted using the keywords "diabetic retinopathy" and "calcium dobesilate". The extracted information included the study design, inclusion and exclusion criteria, setting, sample size, participant mean age, treatment regime, mean change in best corrected visual acuity, laboratory parameters, capillary fragility, intraocular pressure and fundus manifestations based on the findings of fluorescent angiography. The summary statistics indicated that calcium dobesilate was significantly associated with improving retinal microaneurysms ( $R R$ : $0.62,95 \% C I$ : $0.42-0.90, P=0.01)$, retinalhemorrhages $(R R: 0.39,95 \% C I: 0.17-0.88$, $P=0.02)$; exudates $(R R: 0.31,95 \% C I: 0.12-0.81, P=0.02)$, reduction of whole blood viscosity $(M D:-0.57 \mathrm{CP}, 95 \% C I:-0.75$ to $-0.38, P<0.001$ ), plasma viscosity (MD: $-0.36 \mathrm{CP}, 95 \% \mathrm{CI}:-0.63$ to $-0.09, P=0.01$ ) and blood cholesterol (MD: $-0.48 \mathrm{mg}$ $\left.\mathrm{mL}^{-1}, 95 \% C I:-0.64-0.33, P<0.00001\right)$. Intraocular pressure was also significantly reduced $(M D:-5.59 \mathrm{mmHg}, 95 \% C I$ : -6.69 to $-4.50, P<0.00001)$. The results indicate that calcium dobesilate effectively treats DR at the systematic and local ocular levels.
\end{abstract}

diabetic retinopathy, calcium dobesilate, randomized controlled clinical trial, systemic review, meta- analysis

Citation: Zhang XY, Liu W, Wu SS, Jin JL, Li WH, Wang NL. Calcium dobesilate for diabetic retinopathy: a systematic review and meta-analysis. Sci China Life Sci, 2015, 58: 101-107, doi: 10.1007/s11427-014-4792-1

Diabetes and its associated complications continue to be a significant health problem worldwide. Diabetic retinopathy (DR) is the major cause of vision loss and blindness in the working populations of developed countries [1]. Overall, the global rates for proliferative DR, diabetic macular edema and vision-threatening DR are $34.6 \%, 6.96 \%, 6.81 \%$ and $10.2 \%$, respectively [2]. The DR rates in the rural and urban populations of China are $37 \%$ and $42 \%$, respectively [3-5].
Medical treatment can effectively halt the progression of $\mathrm{DR}$, reduce its complication rate and preserve visual function [6]. Several oral medications, including aspirin [7], protein kinase $\mathrm{C}$ inhibitor [8], renin-angiotensin blockade [9] and candesartan [10], effectively inhibit early DR lesions. Calcium dobesilate (2,5-dihydroxybenzenesulfonate) was developed for DR and chronic venous insufficiency more than 40 years ago. This vasoprotective agent was registered by the European Pharmacopoeia in 1997 and the British

*Corresponding author (email: mmzxy2010@163.com) 
Pharmacopoeia in 1998 for treating DR and venous insufficiency. There are seven mechanisms by which calcium dobesilate might treat DR: (i) reducing retinal albumin leakage and capillary permeability, which protects the blood-retinal barrier (BRB) [11]; (ii) inhibiting platelet aggregation and blood viscosity [12]; (iii) up-regulating endothelium-dependent relaxation because of an increase in nitric oxide synthesis [13]; (iv) inhibiting apoptosisof vascular endothelial cells in blood vessels [14]; (v) antioxidant and antiradical activity [15]; (vi) protecting against reactive oxygen species; or (vii) inhibiting the expression of the inflammatory and upstream VEGF regulator, ICAM-1 [16]. These pathological factors are likely the most important inducers of DR.

Calcium dobesilate remains the only angioprotective drug that reduces the progression of DR, according to several randomized clinical trials (RCTs) [17]. Until recently, there has been no global data available concerning the effectiveness of calcium dobesilate in treating DR. Therefore, we performed a meta-analysis of the RCTs that compared calcium dobesilate and placebo treatments to assess the effects of this drug and provide the best treatment regimen for patients with DR. The source materials for this analysis are publicly available.

\section{Methods}

\subsection{Data sources and searches}

We searched MEDLINE, Springer Link and the Cochrane Library for English-language, human-participant, randomized controlled trials (RCTs) published prior to October 31, 2013. We used the following phrases as keywords: "diabetic retinopathy", "calcium dobesilate" and relevant free terms. The Boolean operators "AND", "OR" and "NOT" were used to combine all search sets. References within the retrieved studies were examined for additional trials.

\subsection{Study selection}

RCTs concerning the relevant topic were selected based on the following criteria: (i) the participants were adults with DR; (ii) calcium dobesilate was used as an intervention, and a placebo or non-calcium-dobesilate treatment was used as a control; and (iii) the primary outcomes included microaneurysm, blood viscosity, hemorrhage and exudate improvements as well as capillary closure and mean changes in the visual acuity, intraocular pressure (IOP) and posterior vitreous penetration ratio (PVPR) from baseline to the end of the intervention period.

\subsection{Data extraction and quality assessment}

Two reviewers (XY Zhang and SS Wu) independently assessed the eligibility criteria of all studies and extracted the relevant information using EpiData Version 3.02 (Odense, Denmark). This information included the study author(s), publication year, country, sample size, study duration, intervention and control, mean change in visual acuity, blood viscosity, PVPR from baseline to the end of the intervention period, number of patients whose microaneurysms deteriorated, capillary closure, hemorrhage and exudate and methodology information. The data were sorted using Excel 2007. All discrepancies were resolved by consensus between the assessors.

The quality of the included trials was assessed using the JADAD scale for RCTs [18], which includes an adequate method for randomization, appropriate blinding procedures and a detailed report of withdrawals and dropouts.

\subsection{Data analyses}

Data pooling was performed using Review Manager, Version 5.1 (Copenhagen: The Nordic Cochrane Centre, the Cochrane Collaboration, 2008). Between-group differences in the mean changes of visual acuity, blood viscosity and PVPR were expressed as weighted mean differences (WMDs; i.e., the mean change in the calcium dobesilate group minus that in the control group), with $95 \%$ confidence intervals (CIs). Risk ratios (RRs) were also calculated, with $95 \%$ CIs for the microaneurysm, capillary closure, hemorrhage and exudate improvements. The heterogeneity among studies was evaluated using the $\chi^{2}$ test and $I^{2}$ statistics, and $P<0.1$ was considered to be significant for the heterogeneity test. A random effects model (Mantel-Haenszel) was used to calculate the estimates.

\section{Results}

\subsection{Study characteristics}

A total of 221 studies were initially retrieved. After excluding 57 duplicate reports, four review articles and 34 editorials, comment papers or studies that were not eligible, eight studies met our inclusion criteria and were reviewed in this meta-analysis (see Figure 1 for the study inclusion flow diagram). A total of 552 DR patients were examined among these eight studies, 306 of whom were treated with calcium dobesilate. The mean patient age ranged from 47.28 to 59.19 years old, and the mean duration of diabetes ranged from 3.6 to 15.5 years. The follow-up period ranged from 3 to 24 months. Additional study characteristics are listed in Table 1 [19-26].

\subsection{Quality assessment}

Generally, the quality of the included RCTs was moderate (Table 2) [19-26] . Most RCTs reported the number of participants who were lost to follow-up, whereas the randomization methods used were often unclear. All studies were 


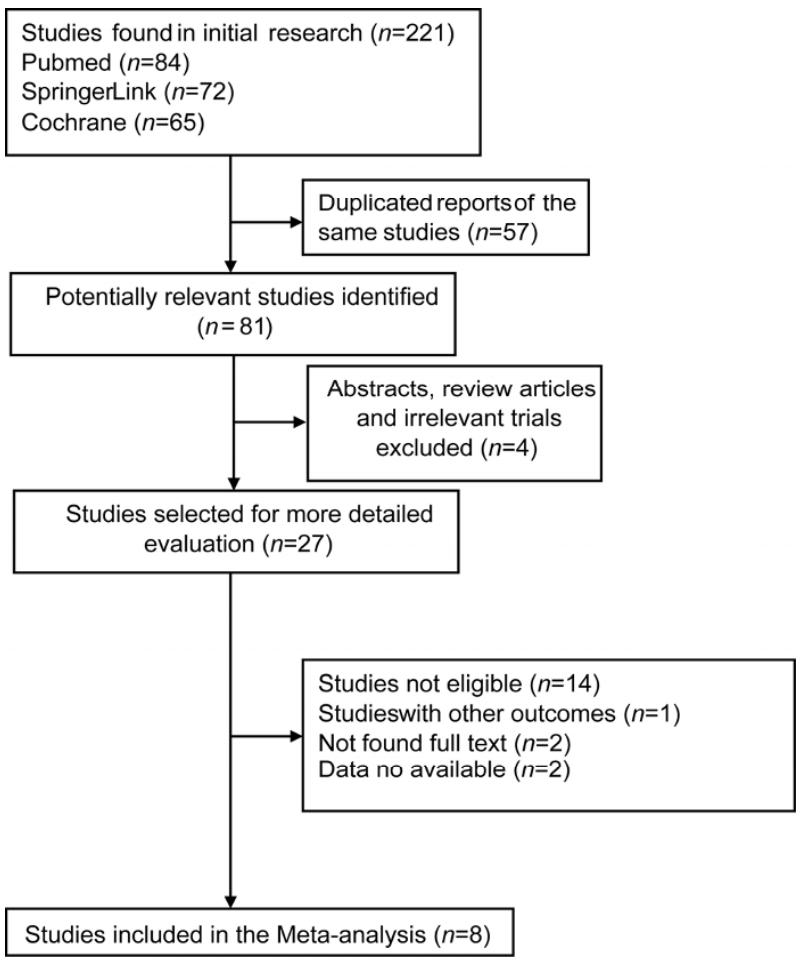

Figure 1 A patient enrollment flow diagram. double blinded.

\subsection{Mean changes in blood viscosity, plasmid viscosity and blood cholesterol}

A random effects model was used to analyze the dependent variables according to the significant heterogeneity of three RCTs with available viscosity data. The pooled mean differences of whole blood and plasma viscosities were -0.57 centipoise (CP) (95\% CI: -0.75 to $-0.38 ; P<0.001$; Figure 2) and -0.36 CP (95\% CI: -0.63 to $-0.09 ; P=0.01$; Figure 3).

Two RCTs reported the data on blood cholesterol reductions. The pooled mean difference of blood cholesterol reduction was $-0.48 \mathrm{CP}(95 \% \mathrm{CI}:-0.64-0.33 ; P<0.00001)$ between calcium dobesilate and placebo groups. However, there were no significant differences in blood glyceride levels between the two groups (MD: $-2.70 \mathrm{mg} \mathrm{mL}^{-1} ; 95 \% \mathrm{CI}$ : $-16.23-10.83 ; P=0.70$; Figure 4).

\subsection{Mean visual acuity change}

We used a random effects model to achieve conservative

Table 1 Characteristics of the studies included in the meta-analysis

\begin{tabular}{|c|c|c|c|c|c|c|}
\hline Study & Country & Follow up duration & Age (years) & Diabetes duration (years) & Control & Intervention (dose, $\mathrm{mg} \mathrm{d}^{-1}$ ) \\
\hline Larsen et al. [19] & Denmark & 8 & 48 & 15.5 & placebo & 750 \\
\hline Vojnikovic et al. [20] & Yugoslav & 6 & 55.17 & 5.05 & Placebo & 1500 \\
\hline Leite et al. [21] & Portugal & 12 & 53.23 & 9.88 & placebo & 2000 \\
\hline Benarroch et al. [22] & Argentina & 3 & 47.28 & 14.5 & placebo & 1500 \\
\hline Vojnikovic et al. [23] & Yugoslava & 3 & 57.98 & 3.6 & placebo & 1500 \\
\hline Benarroch et al. [24] & Argentina & 24 & 47.34 & 2.7 & placebo & 750 \\
\hline Javadzadeh et al. [26] & Iran & 3 & 59.19 & 9.4 & placebo & 500 \\
\hline
\end{tabular}

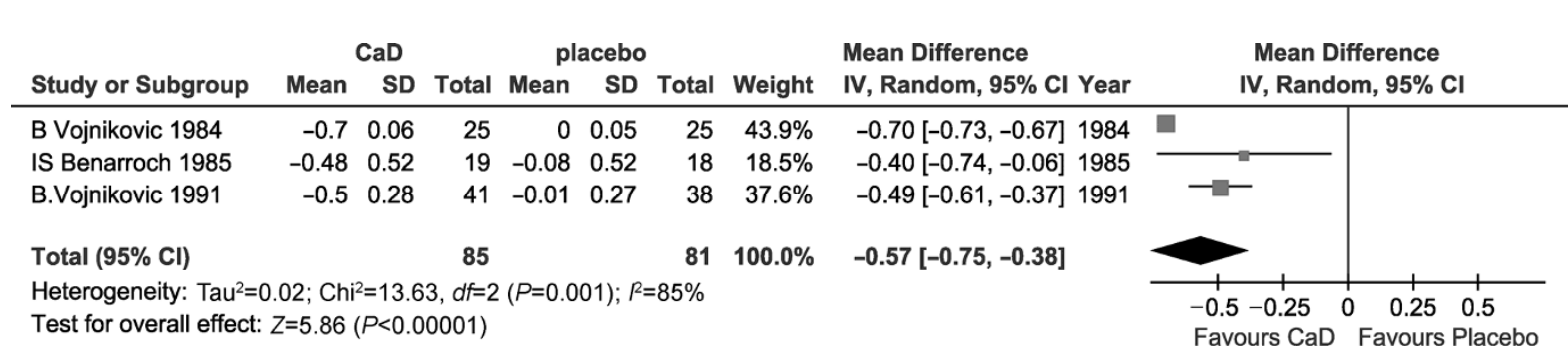

Figure 2 The effectiveness of calcium dobesilate on blood viscosity.

\begin{tabular}{|c|c|c|c|c|c|c|c|c|c|c|}
\hline \multirow[b]{2}{*}{ Study or Subgroup } & \multicolumn{3}{|c|}{$\mathrm{CaD}$} & \multicolumn{3}{|c|}{ placebo } & \multirow[b]{2}{*}{ Weight } & \multirow{2}{*}{$\begin{array}{l}\text { Mean Difference } \\
\text { IV, Random, } 95 \% \text { CI Year }\end{array}$} & \multirow{2}{*}{\multicolumn{2}{|c|}{$\begin{array}{c}\text { Mean Difference } \\
\text { IV, Random, } 95 \% \mathrm{CI}\end{array}$}} \\
\hline & Mean & SD & Total & Mean & SD & Total & & & & \\
\hline B Vojnikovic 1984 & -0.6 & 0.04 & 25 & 0.01 & 0.17 & 25 & $35.1 \%$ & $-0.61[-0.68,-0.54] 1984$ & -7 & \\
\hline IS Benarroch 1985 & -0.05 & 0.29 & 19 & -0.03 & 0.29 & 18 & $30.7 \%$ & $-0.02[-0.21,0.17] 1985$ & & \\
\hline B.Vojnikovic 1991 & -0.4 & 0.23 & 41 & 0.01 & 0.23 & 38 & $34.2 \%$ & $-0.41[-0.51,-0.31] 1991$ & & \\
\hline Total $(95 \% \mathrm{Cl})$ & & & 85 & & & 81 & $100.0 \%$ & $-0.36[-0.63,-0.09]$ & & \\
\hline $\begin{array}{l}\text { Heterogeneity: } \mathrm{Tau}^{2}= \\
\text { Test for overall effect: }\end{array}$ & $\begin{array}{l}.05 ; \mathrm{Chi}^{2} \\
Z=2.59\end{array}$ & $\begin{array}{l}{ }^{2}=38.2 \\
(P=0.1\end{array}$ & $\begin{array}{l}5, d f=2 \\
10)\end{array}$ & $(P<0 . C$ & 0001 & $R=95 \%$ & & & $\begin{array}{ll}-0.5 & -0.25 \\
\text { Favours } \mathrm{CaD}\end{array}$ & $\begin{array}{ccc}0 & 0.25 & 0.5 \\
\text { Favours Placebo }\end{array}$ \\
\hline
\end{tabular}

Figure 3 The effectiveness of calcium dobesilate on plasma viscosity. 
results; however, significant heterogeneity was not observed within two RCTs with available visual acuity data $(P=0.19$, $\left.I^{2}=42 \%\right)$. The pooled mean difference between patients taking calcium dobesilate and those taking a placebo across two RCTs was 0.05 D (95\% CI: 0.00-0.11, P=0.07; Figure 5).

\subsection{Microaneurysm, hemorrhaging, capillary closure and exudates improvements}

\subsubsection{Microaneurysm}

Three RCTs reported the number of patients whose progression deteriorated with regard to microaneurysm, and significant heterogeneity differences did not exist between these RCTs $\left(P=0.91, I^{2}=0 \%\right)$. We used a random effects model to pool the data and observed that the likelihood of microaneurysm improvement significantly increased in the calcium dobesilate group (RR: $0.62,95 \%$ CI: $0.42-0.90$, $P=0.01$; Figure 6).

\subsubsection{Retinal hemorrhages}

Two RCTs provided the improvement count data of retinal hemorrhages. No significant differences in heterogeneity were found between the two RCTs $\left(P=0.20, I^{2}=40 \%\right)$. A random effects model found that the risk of decreased progress toward retinal hemorrhages changed significantly $(R R$ : 0.39, 95\% CI: 0.17-0.88, $P=0.02$; Figure 7).

\subsubsection{Capillary closure}

Two RCTs reported the numbers of patients who demonstrated worse capillary closure progression. Significant heterogeneity was not found between these RCTs $\left(P=0.11, I^{2}=60 \%\right)$. A random effects model revealed that the risk of decreased progress toward capillary closure did not significantly change (RR: 0.87, 95\% CI: 0.08-9.54, P=0.91; Figure 8).

\subsubsection{Exudates}

Two RCTs provided specific information concerning the improvement of retinal exudation. Significant heterogeneity was not observed between these RCTs $\left(P=0.18, I^{2}=45 \%\right)$. A random effects model revealed that the risk of decreased progress toward exudates changed significantly $(R R: 0.31$, 95\% CI: 0.12-0.81, $P=0.02$; Figure 9).

Table 2 The quality of enrolled RCTs $\mathrm{s}^{\mathrm{a})}$

\begin{tabular}{ccccc}
\hline Study & Study type Randomization & Blinding & Lost to follow up \\
\hline Larsen et al. [19] & RCT & 1 & 2 & 1 \\
Vojnikovic et al. [20] & RCT & 1 & 2 & 1 \\
Leite et al. [21] & RCT & 2 & 2 & 1 \\
Benarroch et al. [22] & RCT & 1 & 2 & 1 \\
Vojnikovic et al. [23] & RCT & 1 & 2 & 1 \\
Benarroch et al. [24] & RCT & 1 & 2 & 0 \\
Ribeiro et al. [25] & RCT & 1 & 2 & 4 \\
Javadzadeh et al. [26] & RCT & 2 & 2 & 4 \\
\hline
\end{tabular}

a) DB, double blinding; RCT, randomized clinical trial; estimated effects of calcium obesilate on study characteristics, independent comparisons only $(n=8)$.

\begin{tabular}{|c|c|c|c|c|c|c|c|c|c|}
\hline \multirow[b]{2}{*}{ Study or Subgroup } & \multicolumn{3}{|c|}{ CaD } & \multicolumn{3}{|c|}{ placebo } & \multirow[b]{2}{*}{ Weight } & \multirow{2}{*}{$\begin{array}{l}\text { Mean Difference } \\
\text { IV, Random, } 95 \% \text { CI Year }\end{array}$} & \multirow{2}{*}{$\begin{array}{l}\text { Mean Difference } \\
\text { IV, Random, } 95 \% \mathrm{CI}\end{array}$} \\
\hline & Mean & SD & Total & Mean & SD & Total & & & \\
\hline IS Benarroch 1985 & -0.28 & 0.24 & 19 & 0.2 & 0.24 & 18 & $100.0 \%$ & $-0.48[-0.63,-0.33] 1985$ & \\
\hline A Javadzadeh 2013 & -4.8 & 46.37 & 45 & 2.3 & 55.62 & 45 & $0.0 \%$ & $-7.10[-28.26,14.06] 2013$ & \\
\hline Total $(95 \% \mathrm{Cl})$ & & & 64 & & & 63 & $100.0 \%$ & $-0.48[-0.64,-0.33]$ & \\
\hline \multicolumn{9}{|c|}{$\begin{array}{l}\text { Heterogeneity: } \mathrm{Tau}^{2}=0.00 ; \mathrm{Chi}^{2}=0.38, d f=1(P<0.54) ; P=0 \% \\
\text { Test for overall effect: } Z=6.09(P<0.00001)\end{array}$} & $\begin{array}{ccccc}1 & 1 & 1 & 1 \\
-20 & -10 & 0 & 10 & 20 \\
\text { Favours } \mathrm{CaD} & \text { Favours Placebo }\end{array}$ \\
\hline
\end{tabular}

Figure 4 The effectiveness of calcium dobesilate on blood cholesterol.

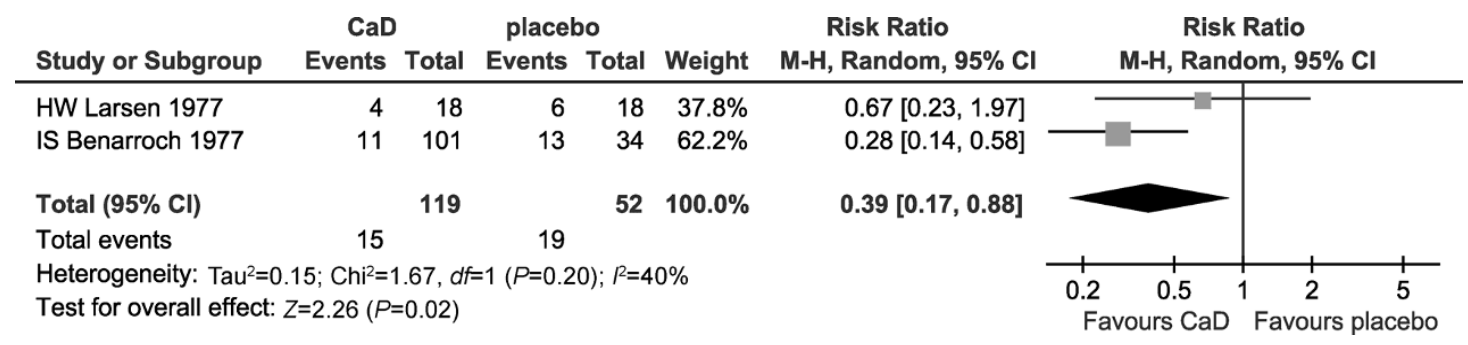

Figure 5 A comparison of the effectiveness of calcium dobesilate on the mean change in visual acuity. 


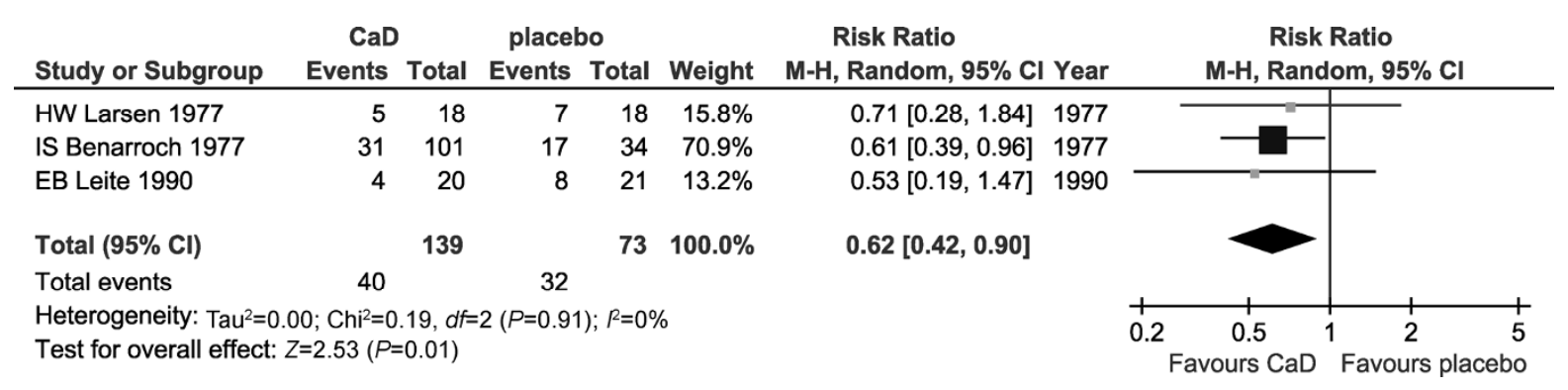

Figure 6 A comparison of the effectiveness of calcium dobesilate on microaneurysm improvement.

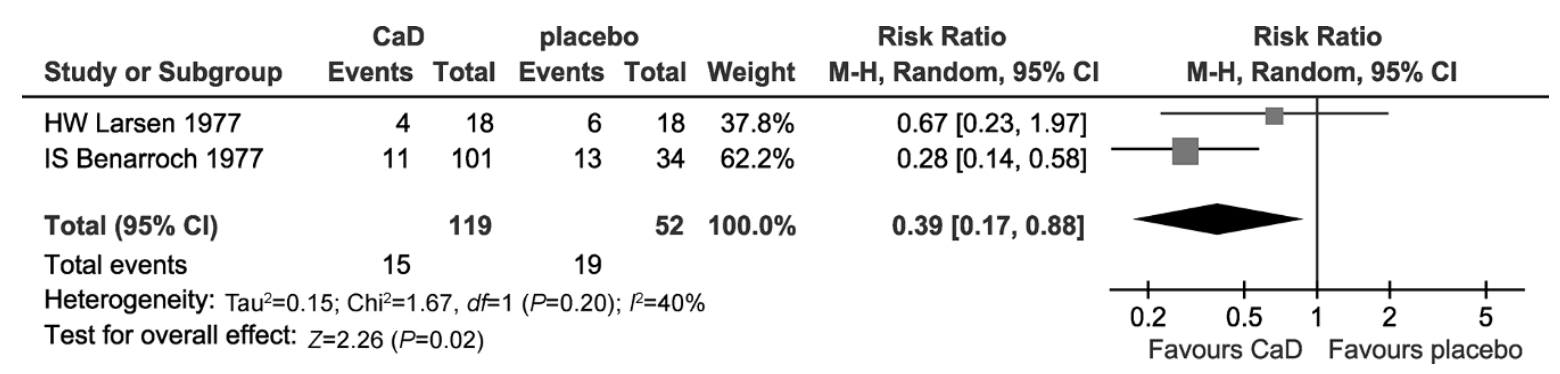

Figure 7 A comparison of the effectiveness of calcium dobesilate on fundus hemorrhage improvement.

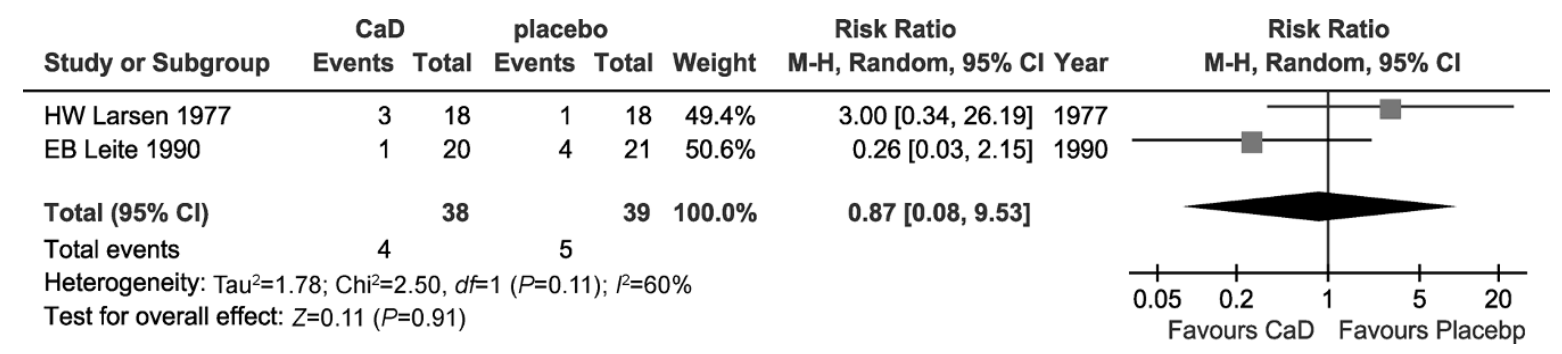

Figure 8 A comparison of the effectiveness of calcium dobesilate on fundus capillary closure improvement.

\begin{tabular}{|c|c|c|c|c|c|c|c|c|}
\hline Study or Subgroup & \multicolumn{2}{|l|}{ CaD } & \multicolumn{2}{|c|}{ placebo } & \multicolumn{3}{|c|}{ Risk Ratio } & $\begin{array}{c}\text { Risk Ratio } \\
\text { M-H, Random, } 95 \% \mathrm{CI}\end{array}$ \\
\hline HW Larsen 1977 & 4 & 18 & 8 & 18 & $50.4 \%$ & $0.50[0.18,1.37]$ & 1977 & - \\
\hline IS Benarroch 1977 & 5 & 101 & 9 & 34 & $49.6 \%$ & $0.19[0.07,0.52]$ & 1977 & \\
\hline Total $(95 \% \mathrm{Cl})$ & & 119 & & 52 & $100.0 \%$ & $0.31[0.12,0.81]$ & & \\
\hline Total events & 9 & & 17 & & & & & \\
\hline $\begin{array}{l}\text { Heterogeneity: } \mathrm{Tau}^{2}= \\
\text { Test for overall effect }\end{array}$ & $\begin{array}{l}\text { 2; } \mathrm{Chi}^{2}=1 \\
=2.40(P=\end{array}$ & $\begin{array}{l}.81, d f= \\
=0.02)\end{array}$ & $=1(P=0.1$ & 8); $P^{2}=45$ & $5 \%$ & & & 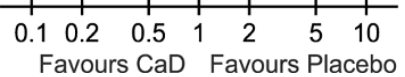 \\
\hline
\end{tabular}

Figure 9 A comparison of the effectiveness of calcium dobesilate on fundus exudate improvement.

\subsection{Reduction of the intraocular pressure}

Two studies reported the reduction of IOP. Significant heterogeneity was found between these two RCTs. The pooled mean differences of IOP reduction between the two groups was $-5.59 \mathrm{mmHg}(95 \% \mathrm{CI}:-6.69$ to $-4.50, P<0.00001$; Figure 10).

\subsection{Mean change in the function of the BRB (i.e., the PVPR)}

Two RCTs reported data concerning a functional evaluation of the BRB. The pooled mean difference in PVPR was -2.77 (95\% CI: $-8.22-2.68, P=0.32$; Figure 11 ).

\section{Discussion}

The results of the present systematic review suggested that an oral intake of $750-2000 \mathrm{mg} \mathrm{d}^{-1}$ of calcium dobesilate effectively treats DR compared with placebo. Microaneurysm, exudates and retinal hemorrhages can be significantly improved; blood parameters, such as whole-blood viscosity, plasma viscosity and cholesterol, were greatly reduced to 


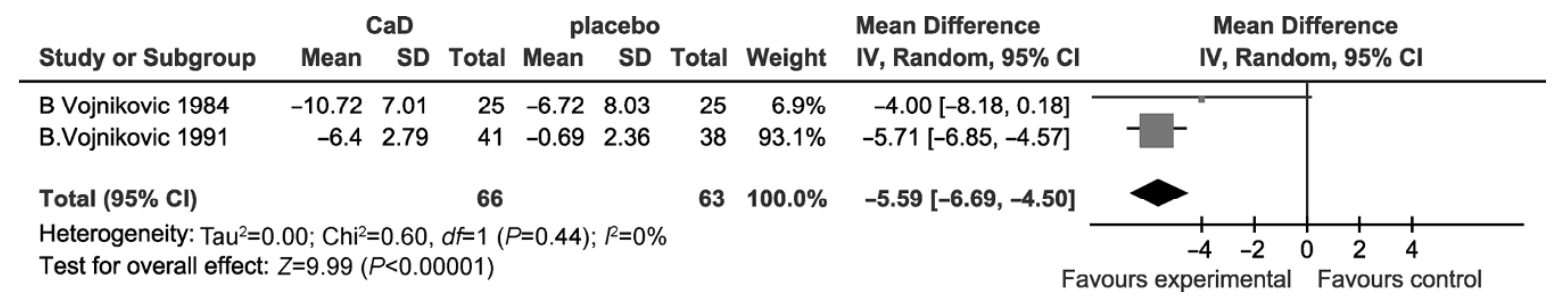

Figure 10 A comparison of the effectiveness of calcium dobesilate on intraocular pressure.

\begin{tabular}{|c|c|c|c|c|c|c|c|c|c|}
\hline \multirow[b]{2}{*}{ Study or Subgroup } & \multicolumn{3}{|c|}{$\mathrm{CaD}$} & \multicolumn{3}{|c|}{ placebo } & \multicolumn{2}{|r|}{ Mean Difference } & \multirow{2}{*}{$\begin{array}{l}\text { Mean Difference } \\
\text { IV, Random, } 95 \% \mathrm{CI}\end{array}$} \\
\hline & Mean & SD & Total & Mean & SD & Total & Weight & IV, Random, $95 \%$ CI Year & \\
\hline EB Leite 1990 & 0.01 & 0.3 & 20 & 0.31 & 0.25 & 21 & $55.9 \%$ & $-0.30[-0.47,-0.13] 1990$ & \\
\hline ML Ribeiro 2006 & -3.87 & 12.03 & 87 & 2.03 & 12.86 & 82 & $44.1 \%$ & $-5.90[-9.66,-2.14] 2006$ & \\
\hline Total $(95 \% \mathrm{Cl})$ & & & 107 & & & 103 & $100.0 \%$ & $-2.77[-8.22,2.68]$ & \\
\hline \multicolumn{9}{|c|}{$\begin{array}{l}\text { Heterogeneity: } \text { Tau }^{2}=13.84 ; \mathrm{Chi}^{2}=8.50, d f=1(P=0.004) ; P=88 \% \\
\text { Test for overall effect: } Z=1.00(P=0.32)\end{array}$} & 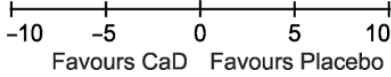 \\
\hline
\end{tabular}

Figure 11 A comparison of the effectiveness of calcium dobesilate on the mean change in function of the blood retinal barrier breakdown (i.e., the PVPR).

normal ranges after a 3-month treatment.

This systematic review examined eight randomized, controlled studies, with a total of 552 patients. All studies fulfilled the inclusion criteria. The large sample size and randomization allocation indicate a substantial increase in statistical precision. The ratio of males to females was approximately equal. The studies were conducted in the US and Europe and involved different races and patient characteristics.

Calcium dobesilate has antioxidant, anti-radical and angioprotective properties. Furthermore, this medicine acts against the capillary permeability induced by reactive oxygen species, enhanced nitric oxide synthase activity in endothelial cells, anti-apoptotic effects in vessels and other tissues and inhibitory effects of inflammatory cytokines. Blood viscosity reductions have been well studied in vivo and in vitro. To our knowledge, this systematic review is the first to evaluate the effectiveness of calcium dobesilate among DR patients on a global basis.

Vascular leakage is a key method of evaluating the effectiveness of calcium dobesilate. The breakdown of the BRB is an early sign of vascular damage. Several methods have been applied to evaluate the function of BRB among RCTs and animal studies, including vitreous fluorophotometry [27], PVPR [25], vascular fragility [28], skin capillary resistance $[19,23]$ and the penetration ratio [21]. Albumin leakage [29] indicates the successful treatment of capillary fragility in DR patients. Although the BRB was significantly protected in these studies, data could not be extracted or pooled together from these studies; thus, a meta-analysis could not be conducted.

Two of the eight studies showed that elevated IOP can be significantly reduced [20,24]. However, more detailed information such as if eye drops were used to control IOP was not provided; furthermore, a large, multi-center study is warranted to confirm the conclusion.

Previous population-based studies [30,31] have shown that hyperlipidemia is a risk factor for developing DR and for the progression of the disease. Hyperlipidemia contributes to DR and ME via endothelial dysfunction and the breakdown of the BRB, which leads to the exudation of serum lipids and lipoproteins. These effects are significantly correlated with DR severity [32-34]. The RCTs examined in this paper confirmed that calcium dobesilate reduces the serum level of blood hyperglycemia; thus, this paper provides justification to prohibit the progression of DR and protect the BRB [23].

The limitations of the current paper include the relatively small sample sizes of the analyzed studies. Furthermore, these data did not originate from multicenter, collaborative studies. A lack of detailed methods regarding the randomization procedures might increase the chances for bias and error. We also recommend that the methodological quality of clinical trials seeking to evaluate drugs be improved in the future using random allocation concealment to prevent selection bias [35] and long-term follow-up assessments that use internationally accepted, uniform and objective indicators of efficacy [36,37]. Furthermore, the negative results, placebo control groups, number of patients lost to follow-up and lost patient records must be reported in detail [38].

This work was partly supported by grant from the National Natural Science Foundation of China (81170859), Bejing Municipal Education Commission Key Project (KZ201210025027) and Beijing Science and Technology New Star Project (2004B28).

1 Blindness caused by diabetes-Massachusetts, 1987-1994. MMWR Morb Mortal Wkly Rep, 1996, 45: 937-941

2 Yau JW, Rogers SL, Kawasaki R, Lamoureux EL, Kowalski JW, Bek T, Chen SJ, Dekker JM, Fletcher A, Grauslund J, Haffner S, Hamman RF, Ikram MK, Kayama T, Klein BE, Klein R, Krishnaiah S, Mayurasakorn K, O'Hare JP, Orchard TJ, Porta M, Rema M, Roy MS, Sharma T, Shaw J, Taylor H, Tielsch JM, Varma R, Wang JJ, Wang 
N, West S, Xu L, Yasuda M, Zhang X, Mitchell P, Wong TY; Meta-Analysis for Eye Disease (META-EYE) Study Group. Global prevalence and major risk factors of diabetic retinopathy. Diabetes Care, 2012, 35: 556-564

3 Xie X, Xu L, Yang H, Wang S, Jonas JB. Frequency of diabetic retinopathy in the adult population in China: the Beijing Eye Study 2001. Int Ophthalmol, 2009, 29: 485-493

4 Xu J, Wei WB, Yuan MX, Yuan SY, Wan G, Zheng YY, Li YB, Wang S, Xu L, Fu HJ, Zhu LX, Pu XL, Zhang JD, Du XP, Li YL, Ji Y, Gu XN, Li Y, Pan SF, Cui XL, Bai W, Chen YJ, Wang ZM, Zhu QS, Gao Y, Liu de Y, Ji YT, Yang Z, Jonas JB. Prevalence and risk factors for diabetic retinopathy: the Beijing Communities Diabetes Study 6. Retina, 2012, 32: 322-329

5 Wang FH, Liang YB, Zhang F, Wang JJ, Wei WB, Tao QS, Sun LP, Friedman DS, Wang NL, Wong TY. Prevalence of diabetic retinopathy in rural China: the Handan Eye Study. Ophthalmology, 2009, 116: $461-467$

6 ACCORD Study Group; ACCORD Eye Study Group, Chew EY, Ambrosius WT, Davis MD, Danis RP, Gangaputra S, Greven CM, Hubbard L, Esser BA, Lovato JF, Perdue LH, Goff DC Jr, Cushman WC, Ginsberg HN, Elam MB, Genuth S, Gerstein HC, Schubart U, Fine LJ. Effects of medical therapies on retinopathy progression in type 2 diabetes. N Engl J Med, 2010, 363: 233-244

7 Vekasi J, Koltai K, Gaal V, Toth A, Juricskay I, Kesmarky G. The effect of aspirin on hemorheological parameters of patients with diabetic retinopathy. Clin Hemorheol Microcirc, 2008, 39: 385-389

8 Aiello LP, Vignati L, Sheetz MJ, Zhi X, Girach A, Davis MD, Wolka AM, Shahri N, Milton RC. Oral protein kinase c beta inhibition using ruboxistaurin: efficacy, safety, and causes of vision loss among 813 patients (1,392 eyes) with diabetic retinopathy in the Protein Kinase $\mathrm{C}$ beta Inhibitor-Diabetic Retinopathy Study and the Protein Kinase C beta Inhibitor-Diabetic Retinopathy Study 2. Retina, 2011, 31: 2084-2094

9 Wilkinson-Berka JL, Rana I, Armani R, Agrotis A. Reactive oxygen species, Nox and angiotensin II in angiogenesis: implications for retinopathy. Clin Sci (Lond), 2013, 124: 597-615

10 Tillin T, Orchard T, Malm A, Fuller J, Chaturvedi N. The role of anthypertensive therapy in reducing vascular complications of type 2 diabetes. Findings from the DIabetic REtinopathy Candesartan Trials-Protect 2 study. J Hypertens, 2011, 29: 1457-1462

11 Ribeiro ML, Caillon P, Gamba G, Cunha-Vaz J, group DX-rs. Efficacy of calcium dobesilate (Doxium(R)) on the blood-retinal barrier permeability in early diabetic retinopathy: a double-blind study. Invest Ophthalmol Vis Sci, 2004, 45: 4153-B614

12 Akbulut B. Calcium dobesilate and oxerutin: effectiveness of combination therapy. Phlebology, 1258, 25: 66-71

13 Ruiz E, Lorente R, Tejerina T. Effects of calcium dobesilate on the synthesis of endothelium-dependent relaxing factors in rabbit isolated aorta. Br J Pharmacol, 1997, 121: 711-716

14 Graber R, Farine JC, Losa GA. Calcium Dobesilate protects human peripheral blood mononuclear cells from oxidation and apoptosis. Apoptosis, 1998, 3: 41-49

15 Szabo ME, Haines D, Garay E, Chiavaroli C, Farine JC, Hannaert P, Berta A, Garay RP. Antioxidant properties of calcium dobesilate in ischemic/reperfused diabetic rat retina. Eur J Pharmacol, 2001, 428: 277-286

16 Opreanu M, Lydic TA, Reid GE, McSorley KM, Esselman WJ, Busik JV. Inhibition of cytokine signaling in human retinal endothelial cells through downregulation of sphingomyelinases by docosahexaenoic acid. Invest Ophthalmol Vis Sci, 1167, 51: 3253-3263

17 Leal EC, Martins J, Voabil P, Liberal J, Chiavaroli C, Bauer J, Cunha-Vaz J, Ambrosio AF. Calcium dobesilate inhibits the alterations in tight junction proteins and leukocyte adhesion to retinal endothelial cells induced by diabetes. Diabetes, 2010, 59: 2637-2645

18 Jadad AR, Moore RA, Carroll D, Jenkinson C, Reynolds DJ, Gavaghan DJ, McQuay HJ. Assessing the quality of reports of randomized clinical trials: is blinding necessary? Control Clin Trials, 1996, 17: $1-12$
19 Larsen HW, Sander E, Hoppe R. The value of calcium dobesilate in the treatment of diabetic retinopathy. A controlled clinical trial. Diabetologia, 1977, 13: 105-109

20 Vojnikovic B. Doxium (calcium dobesilate) reduces blood hyperviscosity and lowers elevated intraocular pressure in patients with diabetic retinopathy and glaucoma. Ophthalmic Res, 1991, 23: 12-20

21 Leite EB, Mota MC, de Abreu JR, Cunha-Vaz JG. Effect of calcium dobesilate on the blood-retinal barrier in early diabetic retinopathy. Int Ophthalmol, 1990, 14: 81-88

22 Benarroch IS, de Salama Benarroch AR, Nano H, Perez H, Bisceglia H. Calcium dobesilate as a treatment for capillary fragility in diabetic retinopathy. Ophthalmologica, 1977, 174: 47-51

23 Benarroch IS, Brodsky M, Rubinstein A, Viggiano C, Salama EA. Treatment of blood hyperviscosity with calcium dobesilate in patients with diabetic retinopathy. Ophthalmic Res, 1985, 17: 131-138

24 Vojnikovic B. Hyperviscosity in whole blood, plasma, and aqueous humor decreased by doxium (calcuim dobesilate) in diabetics with retinopathy and glaucoma: a double-blind controlled study. Ophthalmic Res, 1984, 16: 150-162

25 Ribeiro ML, Seres AI, Carneiro AM, Stur M, Zourdani A, Caillon P, Cunha-Vaz JG. Effect of calcium dobesilate on progression of early diabetic retinopathy: a randomised double-blind study. Graefes Arch Clin Exp Ophthalmol, 2006, 244: 1591-1600

26 Javadzadeh A, Ghorbanihaghjo A, Adl FH, Andalib D, Khojasteh-Jafari H, Ghabili K. Calcium dobesilate reduces endothelin-1 and high-sensitivity C-reactive protein serum levels in patients with diabetic retinopathy. Mol Vis, 2013, 19: 62-68

27 Sander B, Thornit DN, Colmorn L, Strom C, Girach A, Hubbard LD, Lund-Andersen H, Larsen M. Progression of diabetic macular edema: correlation with blood retinal barrier permeability, retinal thickness, and retinal vessel diameter. Invest Ophthalmol Vis Sci, 2007, 48: 3983-3987

28 Benarroch IS, de Salama Benarroch AR, Nano H, Perez H, Bisceglia $\mathrm{H}$. Calcium dobesilate as a treatment for capillary fragility in diabetic retinopathy. Ophthalmologica, 1974, 168: 370-375

29 Zhang X, Bao S, Lai D, Rapkins RW, Gillies MC. Intravitreal triamcinolone acetonide inhibits breakdown of the blood-retinal barrier through differential regulation of VEGF-A and its receptors in early diabetic rat retinas. Diabetes, 2008, 57: 1026-1033

30 Leske MC, Wu SY, Hennis A, Hyman L, Nemesure B, Yang L, Schachat AP. Hyperglycemia, blood pressure, and the 9-year incidence of diabetic retinopathy: the Barbados Eye Studies. Ophthalmology, 2005, 112: 799-805

31 Varma R, Macias GL, Torres M, Klein R, Pena FY, Azen SP. Biologic risk factors associated with diabetic retinopathy: the Los Angeles Latino Eye Study. Ophthalmology, 2007, 114: 1332-1340

32 Benarous R, Sasongko MB, Qureshi S, Fenwick E, Dirani M, Wong TY, Lamoureux EL. Differential association of serum lipids with diabetic retinopathy and diabetic macular edema. Invest Ophthalmol Vis Sci, 1167, 52: 7464-7469

33 Agroiya P, Philip R, Saran S, Gutch M, Tyagi R, Gupta KK. Association of serum lipids with diabetic retinopathy in type 2 diabetes. Indian J Endocrinol Metab, 2013, 17: S335-337

34 Landmesser U, Hornig B, Drexler H. Endothelial dysfunction in hypercholesterolemia: mechanisms, pathophysiological importance, and therapeutic interventions. Semin Thromb Hemost, 2000, 26: 529-537

35 Schulz KF, Grimes DA. Generation of allocation sequences in randomised trials: chance, not choice. Lancet, 2002, 359: 515-519

36 Glasziou P, Chalmers I, Rawlins M, McCulloch P. When are randomised trials unnecessary? Picking signal from noise. BMJ, 2007, 334: $349-351$

37 Guyatt GH, Oxman AD, Kunz R, Vist GE, Falck-Ytter Y, Schunemann HJ. What is "quality of evidence" and why is it important to clinicians? BMJ, 2008, 336: 995-998

38 Charles P, Giraudeau B, Dechartres A, Baron G, Ravaud P. Reporting of sample size calculation in randomised controlled trials: review. BMJ, 2009, 338: b1732

Open Access This article is distributed under the terms of the Creative Commons Attribution License which permits any use, distribution, and reproduction in any medium, provided the original author(s) and source are credited. 